\title{
Human Exploitation of Aquatic Landscapes. Editorial
}

\section{$\underline{\text { Ricardo Fernandes }}^{1,2,3}$ and $\underline{\text { Lhn Meadows }}^{2,4}$}

Cite this as: Fernandes, R. and Meadows, J. (2014). Human Exploitation of Aquatic Landscapes. Editorial. Internet Archaeology, (37). http://dx.doi.org/10.11141/ia.37.11

1. Institute for Ecosystem Research, University of Kiel. Email: rfernandes@gshdl.uni-kiel.de

2. Leibniz Laboratory for Radiometric Dating and Isotope Research, University of Kiel. Email: jmeadows@leibniz.uni-kiel.de

3. McDonald Institute for Archaeological Research, University of Cambridge. Email: rf385@cam.ac.uk

4. Centre for Baltic and Scandinavian Archaeology, Schloss Gottorf.

This issue has been funded by the Graduate School "Human Development in Landscapes", University of Kiel with additional funding from the Institute for Ecosystem Research, University of Kiel and the Centre for Baltic and Scandinavian Archaeology, Schloss Gottorf.

(C) Author(s). Except where otherwise noted, content from this work may be used under the terms of the Creative Commons Attribution 3.0 Unported licence, which permits unrestricted use, distribution, and reproduction in any medium, provided that attribution to the author(s), the title of the work, the Internet Archaeology journal and the relevant URL/DOI is given. 
Aquatic landscapes such as rivers, lakes, and seas played an important role in past human behaviour, affecting modes of subsistence, patterns of mobility, access to material resources, and technological choices and their developments. The interaction with aquatic landscapes was also influential in the establishment of economic and social structures and in the formation of communal identities. The aim of this special themed issue of Internet Archaeology is to contribute to a better understanding of different forms of human interaction with aquatic landscapes. A brief summary is given below of all issue contributions.

The earliest case study is by Goren-Inbar et al. and refers to the Acheulian (Lower Palaeolithic) site of Gesher Benot Ya'aqov in Israel. Excavated archaeological horizons revealed the presence of significant amounts of fragments of the water lily Euryale ferox and of pitted stones showing wear patterns consistent with the processing of E. ferox. A careful study of the site's taphonomy demonstrated that hominins were the agents responsible for the accumulation of Euryale ferox fragments. Drawing on Indian ethnographical examples of $E$. ferox seed consumption, Goren-Inbar et al. showed that multistage processing would be required, providing important insights into the cognitive abilities of past hominins.

Meredith-Williams et al. report the discovery, using satellite imagery and predictive site location models, of 4,200 shell midden sites dating to the Middle Holocene in the Farasan and Dahlak Archipelagos in the southern Red Sea. Given observed similarities in shell midden sites on both coasts, the authors put forward the hypothesis of possible regular crossings of the Red Sea by past hunter-fisher-gatherer communities.

Philippsen and Meadows use radiocarbon and stable isotope carbon and nitrogen analyses to detect fish residues in Mesolithic Ertebølle pottery from northern Germany. Carbon isotope signatures provide a clear separation between carbonised food crusts on pots from Baltic coastal sites, used to cook marine foods, and those from inland sites used to cook freshwater fish. The prevalence of aquatic foods implies that radiocarbon dates on food crusts from Ertebølle pottery are likely to be anomalously old, given the lower radiocarbon content of local fish, especially in freshwater contexts.

Glykou studied faunal remains from the submerged site of Neustadt, located in the Lübeck bay of the southern Baltic Sea in northern Germany. Radiocarbon dates place site occupation between 4400 and 3800 cal BCE, which covers the local Mesolithic-Neolithic transition. Some 4,000 fragments from mammals, birds and amphibians have been identified from a total of $c .12,000$ collected bones. Age estimations from seal bone material show that grey and harp seals were hunted on a seasonal basis. Neolithic elements such as Funnel Beaker pottery and domesticated cattle are gradually introduced at Neustadt, but faunal data show continuity in the exploitation of marine food resources into the Neolithic. 
Linderholm et al. use a combination of carbon, nitrogen, and sulphur isotope data to investigate dietary habits and migration patterns of Neolithic and Bronze Age individuals from the island of Öland in Sweden. For some individuals, changes in dietary habits are also examined by comparing isotope data from tooth dentine and bone collagen, since these tissues are formed at different ages. Relying on isotope data from potential food groups, Linderholm et al. developed a linear model to separate mobility and dietary signals. Patterns of higher mobility, defined by a higher proportion of individuals of non-local origin or who changed residence, were more prevalent in the Bronze Age than during the Neolithic. Linderholm et al. associate this phenomenon with an intensification of contacts with continental Europe.

Mougne et al. provide strong evidence for the consumption of marine foods at the Bronze Age site of Clos des Châtaigniers (Normandy, France), located $10 \mathrm{~km}$ from the coastline. Large burnt mussel shells demonstrate that mussels were collected along the coast in the intertidal zone and transported inland for human consumption. Smaller marine shells were unburnt and it is hypothesised that these could originate from the stomach contents of fish. This case study is placed within the larger context of the widespread exploitation of marine foods in Normandy during the Bronze and Iron Ages.

Morales and Horton investigate how aquatic subsistence strategies varied spatially and chronologically along the Swahili coast of East Africa between 700 and 1400 CE. Given the connection between fish species and their habitats and particular fishing strategies, Morales and Orton reconstruct past fishing activities from the identification of archaeological fish remains. Although fish from more accessible habitats were always preferentially exploited, differences in assemblage composition indicate the use of different fishing strategies between settlements. In particular, during the second millennium CE open-sea fishing was observed only in richer settlements.

Orijemie reports the results of palynological and archaeological research at the site of Ahanve in coastal south-western Nigeria. Archaeological deposits show that freshwater and marine resources, such as fish, mussels, and salt, were regularly exploited between the 9th and 17th centuries CE. The decline and eventual disappearance of these resources appears to coincide with the local arrival of Europeans, indicated by the presence of European-type smoking pipes in the archaeological record. Oral tradition suggests that the drastic change in the exploitation of aquatic resources was a response to the trans-Atlantic slave trade.

Campbell and Russell investigate deposits, dating to the early modern period, of wellpreserved whelks from the site of Carisbrooke Castle on the Isle of Wight, in southern England. The study of shell damage patterns suggests that the whelks were harvested, probably from fast tidal flows, by bottom-fishing. Specifically, the damage pattern suggests repeated trawling. According to the authors, this is likely to constitute the first instance in 
which bottom-fishing for whelks, incidental to oystering, has been established through the analysis of shell damage.

Dunn and Meide describe the communal living habits of 19th to early 20th century inhabitants of Achill Island in Ireland. United by a strong sense of identity, the islanders actively engaged with the local marine landscape. The sea represented the link with offisland destinations, marine fish provided a cheap source of protein, and seaweeds were intentionally propagated and then used as an agricultural fertilizer. Relying on documentary evidence, Dunn and Meide demonstrate how the local inhabitants resisted strong external pressures to modify their traditional modes of living.

Unavoidably, this issue is only a brief and fragmentary survey of the many types of situations in which humans depended on the exploitation of aquatic environments; however, the following provides a few concluding remarks:

- Both foraging societies and farmers may rely heavily on aquatic resources, in both tropical and temperate environments.

o Past use of aquatic resources can be investigated using many different techniques, from classic excavation and taxonomic determination of plant and animal remains, to microscopic use-wear analysis, interpretation of isotopic tracers, remote sensing, and documentary, photographic and oral history.

o What appears to be a food resource may have been acquired incidentally, or may be present owing to natural processes, and aquatic resources may have been acquired to serve as inputs for terrestrial subsistence economies (e.g. animal feed, fertilizer, salt).

o The political and economic context, as well as the natural environment, have to be considered when interpreting changing patterns of aquatic resource use; while the impact of human exploitation on the natural availability of aquatic resources was not a focus of discussion in this issue, it is evident that social complexity and participation in exchange networks are at least as important in determining which resources are exploited as the perceived risks and returns based on natural availability. 